\title{
Comparison of Ultrasound Cephalometry, Radiology, and Liquor Studies in Patients with Unknown Confinement Dates*
}

\author{
ROSEMARY A. UNDERHILL, JOHN M. BEAZLEY, STUART CAMPBELL
}

British Medical fournal, 1971, 3, 736-738

\section{Summary}

The accuracy of predicting fetal maturity by ultrasound cephalometry, radiology, and liquor studies in patients with unknown confinement dates has been compared. The best prediction was given by ultrasound cephalometry. Liquor studies were least helpful.

\section{Introduction}

Modern antenatal care demands an accurate assessment of fetal maturity. Traditionally, this is based on a prediction of the confinement date (E.D.C.), calculated by Naegele's rule from the first day of the last menstrual period (L.M.P.). We have shown previously that in $22 \%$ of the patients attending the antenatal clinic it is impossible to predict the E.D.C. by Naegele's rule for several reasons and that in these patients the perinatal mortality ratio is 73 , compared with 15 in those whose E.D.C. is known (Beazley and Underhill, 1971).

Clinical examination of the uterine fundus during pregnancy has been shown to be an inaccurate method of estimating fetal maturity (Beazley and Underhill, 1970). In this paper, therefore, results are presented of a study undertaken to predict an E.D.C. by ultrasound cephalometry, radiology, and liquor examination in patients whose confinement date is unknown.

\section{Patients and Methods}

Patients with an unknown E.D.C. who were admitted to this university unit at Queen Charlotte's Maternity Hospital between March 1969 and January 1971 have been studied. Their E.D.C. was considered unknown when the date of the L.M.P. was unknown; the menstrual cycle was irregular and 35 days or longer; bleeding which could be confused with a period occurred in early pregnancy; or conception occurred before the return of the menses following a previous pregnancy or oral contraception.

When possible the following tests were done: (1) measurement of the fetal biparietal diameter by ultrasound, and prediction of the E.D.C. by the method of Campbell (1969) and with the graphs of Campbell and Newman (1971); (2) an $x$-ray film in late pregnancy to assess fetal maturity by the method of Hartley (1957); and (3) abdominal amniocentesis to aspirate $10-15 \mathrm{ml}$ of liquor amnii in late pregnancy, following ultrasound placentography. In one aliquot the cells were stained with Nile blue sulphate to assess fetal maturity by the method of Brosens and Gordon (1966). In some samples a second aliquot was used to -Some of the results in this paper were included in a prize-winning essay
presented by R.A.U. for the Queen Charlotte's and Chelsea Hospital presented by R.A.U.

Institute of Obstetrics and Gynaecology, Queen Charlotte's Maternity Hospital, London W.6

ROSEMARY A. UNDERHILL, F.R.C.S., D.A., Senior House Officer (At present, Registrar, West London Hospital (Charing Cross Group), London $\mathbf{W 6}$

JOHN M. BEAZLEY, M.D., M.R.C.0.G., Senior Lecturer

STUART CAMPBELI, M.B., M.R.G.O.G., Senior Lecturer determine the liquor creatinine concentration (Lind, Parkin, and Cheyne, 1969).

In patients who delivered spontaneously the E.D.C. predicted by the tests was compared with the actual date of confinement. When induction of labour was recommended by the obstetrician in charge the results of the tests were used to decide the optimum time. Whenever possible, induction of labour for suspected prolonged pregnancy was avoided.

\section{Results}

There were 344 patients with an unknown E.D.C. Labour began spontaneously in 284 and in 222 of these the date of confinement was predicted by tests.

Predictions by Ultrasound.-The accuracy of prediction of the E.D.C. in 201 patients, calculated by ultrasound cephalometry, is shown in Table I. Delivery occurred within one week before to one week after the predicted date in $49 \%$ and within two weeks before to two weeks after in $73 \%$. These results were improved to $54 \%$ and $80 \%$ respectively in 143 of the women whose fetal biparietal diameter at ultrasound was equivalent to 30 weeks' gestation or less and whose babies weighed more than $2.5 \mathrm{~kg}$ at birth (Table I).

TABLE I-Accuracy of Prediction of E.D.C. by Ultrasound Cephalometry

\begin{tabular}{|c|c|c|c|c|}
\hline \multirow{3}{*}{ Actual Time of Delivery } & \multirow{2}{*}{\multicolumn{2}{|c|}{$\begin{array}{c}\text { Uncorrected } \\
\text { Patients } \\
\end{array}$}} & \multirow{2}{*}{\multicolumn{2}{|c|}{$\begin{array}{c}\text { Corrected* } \\
\text { Patients }\end{array}$}} \\
\hline & & & & \\
\hline & No. & $\%$ & No. & $\%$ \\
\hline $\begin{array}{l}\text { 74 weeks before the E.D.C. } \\
\text { 4-3 weeks before the E.D.C. } \\
\text { 3-2 weeks before the E.D.C. } \\
\text { 2-1 week before the E.D.C. }\end{array}$ & $\begin{array}{r}9 \\
12 \\
12 \\
30\end{array}$ & $\begin{array}{r}5 \\
6 \\
6 \\
15\end{array}$ & $\begin{array}{r}3 \\
1 \\
9 \\
22 \\
\end{array}$ & $\begin{array}{r}2 \\
1 \\
7 \\
15\end{array}$ \\
\hline 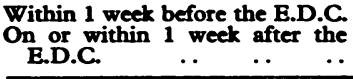 & $\begin{array}{l}51 \\
46\end{array}$ & $\begin{array}{l}26 \\
23\end{array}$ & $\begin{array}{l}40 \\
37\end{array}$ & 26 \\
\hline $\begin{array}{l}\text { 1-2 weeks after the E.D.C. } \\
\text { 2-3 weeks after the E.D.C. } \\
\text { 3-4 weeks after the E.D.C. } \\
>4 \text { weeks after the E.D.C. }\end{array}$ & $\begin{array}{r}19 \\
12 \\
5 \\
5\end{array}$ & $\begin{array}{l}9 \\
6 \\
2 \\
2\end{array}$ & $\begin{array}{r}16 \\
7 \\
5 \\
3 \\
\end{array}$ & $\begin{array}{r}11 \\
5 \\
3 \\
2 \\
\end{array}$ \\
\hline Total & 201 & 100 & 143 & 100 \\
\hline
\end{tabular}

- Ultrasound cephalometry performed before the biparietal diameter exceeds $8.2 \mathrm{~cm}$ (equivalent to 30 weeks' gestation), and excluding infants $2.5 \mathrm{~kg}$ or less at birth.

Predictions by Radiology. - The accuracy of prediction of the E.D.C. calculated from an $x$-ray film in 110 patients is shown in Table II. Delivery occurred within one week before and after the predicted date in $32 \%$ and within two weeks before and after in $63 \%$. If seven patients whose babies weighed $2.5 \mathrm{~kg}$ at birth are excluded from these results they are improved to $33 \%$ and $66 \%$ respectively.

Predictions by Liquor Amnii.-With liquor amnii studies it is possible to predict only an interval during which or a date by which delivery should occur. In this investigation the results of cytological staining by Nile blue sulphate were reported as "less than 34 weeks," "34-38 weeks," "38-40 weeks," or "ovier 40 weeks" (Brosens and Gordon 1966). The accuracy of prediction with this method is shown in Table III. In this study $55 \%$ of patients delivered within the interval of time predicted by the test, but this was as long as a month in some cases. The 
TABLE II-Accuracy of Prediction of E.D.C. by Antenatal X-Ray

\begin{tabular}{|c|c|c|c|c|}
\hline \multicolumn{3}{|c|}{ Actual Time of Delivery } & \multicolumn{2}{|c|}{ Patients } \\
\hline & & & \multirow{2}{*}{$\begin{array}{r}\text { No. } \\
5 \\
7 \\
13 \\
17\end{array}$} & \multirow{2}{*}{$\begin{array}{r}\% \\
4 \cdot 0 \\
6 \cdot 0 \\
12 \cdot 0 \\
15 \cdot 5\end{array}$} \\
\hline $\begin{array}{l}\text { 74 weeks before the E.D.C. } \\
4-3 \text { weeks before the E.D.C. } \\
\text { 3-2 weeks before the E.D.C. } \\
\text { 2-1 week before the E.D.C. }\end{array}$ & $\begin{array}{ll}\cdots & \cdots \\
\cdots & \cdots \\
\cdots & \cdots\end{array}$ & $\begin{array}{l}\cdots \\
\therefore \\
\cdots\end{array}$ & & \\
\hline $\begin{array}{l}\text { Within } 1 \text { week before the E.D } \\
\text { On or within } 1 \text { week after the }\end{array}$ & E.D.C. $\cdots$ & $\because$ & $\begin{array}{l}17 \\
18\end{array}$ & $\begin{array}{l}15 \cdot 5 \\
16 \cdot 5\end{array}$ \\
\hline \multirow[t]{2}{*}{$\begin{array}{l}\text { 1-2 weeks after the E.D.C. } \\
\text { 2-3 weeks after the E.D.C. } \\
\text { 3-4 weeks after the E.D.C. } \\
>4 \text { weeks after the E.D.C. }\end{array}$} & $\begin{array}{l}\ddot{*} \\
\ddot{*}\end{array}$ & $\begin{array}{l}\ddot{*} \\
\ddot{*}\end{array}$ & $\begin{array}{r}17 \\
6 \\
8 \\
2\end{array}$ & $\begin{array}{r}15 \cdot 5 \\
6 \cdot 0 \\
7 \cdot 0 \\
2 \cdot 0\end{array}$ \\
\hline & Total & .. & 110 & 100 \\
\hline
\end{tabular}

TABLE III-Accuracy of Prediction of Interval for Delivery with Liquor Studies

\begin{tabular}{l|r|r}
\hline \multirow{2}{*}{ Actual Time of Delivery } & \multicolumn{2}{|c}{ Patients } \\
\cline { 2 - 3 } & No. & $\%$ \\
\hline More than 2 weeks before the predicted interval & 1 & 2 \\
Within 2 weeks before the predicted interval .. & 5 & 11 \\
\hline Within the predicted interval* .. .. .. & 24 & 55 \\
\hline Within 2 weeks after the predicted interval .. & 11 & 25 \\
More than 2 weeks after the predicted interval & 3 & 7 \\
\hline Total .. & 44 & 100 \\
\hline
\end{tabular}

*In some patients the predicted interval was as long as one month.

creatinine concentration, determined in some of the liquor samples, did not improve the accuracy of prediction.

Predictions by Ultrasound and X-Ray Film Compared.-There were 88 patients who had both ultrasound and radiological predictions of an E.D.C. Ultrasound gave the best prediction in $44 \%$ of them, radiology was better in $34 \%$, and in $22 \%$ both tests were equally good.

Predictions by Ultrasound, X-Ray Film, and Liquor Studies Compared.-There were 38 patients in whom amniocentesis was done in addition to both ultrasound cephalometry and abdominal $x$-ray examination. In only one of these patients did liquor studies provide a better indication of fetal maturity than the other two tests. This patient was insonated late in pregnancy, which is not the optimal time for assessment of fetal maturity. The baby weighed more than $4 \mathrm{~kg}$ at birth. A comparison of predictions by liquor studies and $x$-ray examination, undertaken in 41 patients, shows that the liquor technique was better in only four. Among 41 women who had both amniocentesis and ultrasound, liquor studies were more accurate in only two.

Fetal Hazards.-Dysmaturity or poor fetal growth occurred in 30 patients, and in eight of these the baby died. Table IV

TABLE IV-Perinatal Mortality*

\begin{tabular}{|c|c|c|c|c|c|}
\hline & & & Perinatal Deaths & $\begin{array}{l}\text { Total No. of } \\
\text { Patients }\end{array}$ & Perinatal Mortality \\
\hline \multirow[t]{2}{*}{$\begin{array}{l}\text { 1st year } \\
\text { 2nd year }\end{array}$} & $\ldots$ & $\because$ & $\begin{array}{r}10 \\
5\end{array}$ & $\begin{array}{l}165 \\
179\end{array}$ & $\begin{array}{l}61 \\
28\end{array}$ \\
\hline & Total & .. & 15 & 344 & 44 \\
\hline
\end{tabular}

*Stillbirths and neonatal deaths per 1,000 births corrected for gross fetal abnormality.

shows the perinatal mortality ratio corrected for gross fetal abnormality in all patients with an unknown E.D.C. During the second year of the study the ratio was more than halved. There was also a concurrent fall from $19 \%$ to $14 \%$ in the incidence of babies born with an Apgar score of less than five. These reductions were associated with the use of tests in only $5 \%$ more patients, but the use of ultrasound in $14 \%$ more patients. Also the induction of labour for all reasons increased in the second year from $13 \%$ to $22 \%$. This increase was not associated with an increase in the number of babies weighing less than $2.5 \mathrm{~kg}$ at birth.

Though fetal maturity can be calculated from liquor studies, the method is very inexact (Brosens and Gordon, 1966). In our view liquor examination may indicate either that a fetus is unlikely to die of prematurity if labour is induced ( $>10 \%$ cells) or that it is mature ( $>50 \%$ cells). When there are less than $10 \%$ cells estimation of maturity cannot be made (Chan, Willis, and Woods, 1969).

In the management of patients whose confinement date cannot be calculated it is recommended that whenever possible estimation of the uterine size should be made in early pregnancy by bimanual examination (Beazley and Underhill, 1970). Subsequently, ultrasound cephalometry should be performed routinely and an E.D.C. predicted. If there is clinical suspicion of poor fetal growth the test should be repeated. An $x$-ray film to confirm fetal maturity should be taken as near term as possible, especially before induction of labour or elective caesarean section. If, after these measures, serious doubts about fetal maturity remain examination of the liquor amnii may prove helpful. 
We accept that facilities for ultrasound cephalometry are not always available and that during pregnancy $x$-ray examination may be undesirable. Furthermore, amniocentesis, which can be uncomfortable for the patient, is dangerous without previous placentography. Fetal hazards, however, may be reduced by the increased, but judicious, use of these tests in patients with an unknown confinement date.

We wish to thank Dr. J. H. Smitham, consultant radiologist, Dr. M. Sandler, consultant chemical pathologist, and Dr. J. PryseDavies, consultant pathologist, for their help with this study.

\section{References}

Beazley, J. M., and Underhill, R. A. (1970). British Medical fournal, 4, 404 Beazley, J. M., and Underhill, R. A. (1971). In Press.

Brosens, I., and Gordon, H. (1966). Fournal of Obstetrics and Gynaecology of the British Commonevealth, 73, 88.

Campbell, S. (1969). Fournal of Obstetrics and Gynaecology of the British Commonrvealth, 76, 603.

Campbell, S., and Newman, G. B. (1971). fournal of Obstetrics and Gynaecology of the British Commonevealth, 78, 513.

Chan, W. H., Willis, J., and Woods, J. (1969). Fournal of Obstetrics and Gynaecology of the British Commonevealth, 76, 193.

Hartley, J. B. (1957). British fournal of Radiology, 30, 561.

Lind, T., Parkin, F. M., and Cheyne, G. A. (1969). Fournal of Obstetrics and Gynaecology of the British Commonwealth, 76, 673.

Park, G. L. (1968). Lancet, 2, 1388.

Russel, j. (1969). Fournal of Obstetrics and Gynaecology of the British Commonwealth, 76, 208 .

\title{
Trimethoprim and Sulphamethoxazole in Typhoid Fever in Children
}

\author{
J. N. SCRAGG， C. J. RUBIDGE
}

British Medical fournal, 1971, 3, 738-741

\section{Summary}

One hundred and three children with proved typhoid fever were treated with trimethoprim-sulphamethoxazole, and the results compared with those of a further $\mathbf{4 0}$ children treated with chloramphenicol. The bacteriological response to trimethoprim-sulphamethoxazole was unsatisfactory. From this study it seems that at present chloramphenicol is still the treatment of choice for typhoid fever. In view of the haematological changes occurring during therapy with trimethoprim-sulphamethoxazole caution is necessary and monitoring of the blood picture advisable, even at the recommended dose.

\section{Introduction}

Our considerable experience in the treatment of typhoid fever with chloramphenicol (Scragg et al., 1969) indicated that a 21-day course of therapy was necessary to keep the relapse rate of this disease at a low level. The manufacturers of the drug combination trimethoprim-sulphamethoxazole claim success in the treatment of salmonella infections, the recommended course being 14 days.

The purpose of this study was to establish if this drug combination achieved the same satisfactory response both clinically and bacteriologically that chloramphenicol has given. If it did, and was also able to shorten the duration of therapy and thereby hasten discharge from hospital, this would be an advance in therapeutic management.

\section{Patients and Methods}

During the study period (September 1969 to April 1971) 240 cases of typhoid were admitted to this unit. There were 12 deaths, nine of them occurring shortly after admission and

Department of Paediatrics and Child Health, University of Natal, Durban, South Africa

J. N. SCRAGG, M.D., D.C.H., Principal Paediatrician/Senior Lecturer C. J. RUBIDGE, M.B., D.C.H., Senior Paediatrician/Senior Lecturer before treatment could be instituted. Of the remaining three the diagnosis was not suspected before death in two; the third child is included in this trial. A further 85 cases were excluded from the series because Salmonella typhi was not isolated from the blood culture. One hundred and forty-four symptomatic cases of typhoid fever, all proved by isolation of Salm. typhi in blood and/or clot culture, are therefore included in this study.

At the start of the study we decided to treat all cases with trimethoprim-sulphamethoxazole. When it was apparent that the response in the first $\mathbf{4 0}$ cases was disappointing we thought it wise to compare the therapeutic response with that to chloramphenicol during this epidemic to confirm our past experience of its efficacy. Thus as the study proceeded typhoid admissions to two wards were given trimethoprim-sulphamethoxazole while those to another two wards were treated with chloramphenicol. All the cases were under our personal care.

One hundred and four patients received the drug on trial and 40 received chloramphenicol (Parke Davis). On admission, in addition to positive blood cultures, 22 had positive stool cultures, nine positive urine cultures, and nine positive cultures for both stool and urine. Most had significantly raised agglutination titres.

After the initial cultures of blood, stool, and urine on admission, blood cultures were repeated during the period of therapy in $114(80 \%)$. Stool and urine samples were cultured after cessation of the drugs until at least three successive negative cultures were obtained for each. Full blood counts were done before therapy in all patients (see Table II). Thereafter they were repeated throughout the period of therapy at least biweekly and more often if indicated. Absolute platelet counts were done in only 50 patients. In a further 59 the platelets were reported as normal or reduced in numbers from the study of the peripheral blood smears. In-vitro sensitivity tests were not possible in all cases. However, this test was done in 68 of the trimethoprim-sulphamethoxazole group. Salm. typhi was tested against the drug combination but not to each separate component.

\section{DOSAGE SCHEDULES}

Trimethoprim-Sulphamethoxazole.-We undertook to administer two "paediatric" tablets 12-hourly for 14 days. Thus, initially, the dose was not based on the weight of the patient. After 